\title{
Co-morbidity of Attention Deficit / Hyperactivity Disorder among A Sample of Egyptian Children with Idiopathic Epilepsy Attending Outpatient Clinic in Al Hussein University Hospital Mohamed Abdalla Ghowinam ${ }^{1}$, Mahrous Ibrahim Seddeek ${ }^{2}$ \\ 1 Department of Psychiatry, 2Department of Neurology, Al-Azhar University, Cairo, Egypt
}

\begin{abstract}
Background: Attention deficit/hyperactivity disorder (ADHD) is a complex disorder that affects about 5:8\% of school-aged children worldwide. Many researchers reported increased prevalence of ADHD among epileptic children. Objectives: Detection of the prevalence of ADHD among a sample of Egyptian epileptic children attending $\mathrm{Al}$ Hussein University Hospital, Neurology clinic, \& determination of associated risk factors.

Methods: A cross-sectional study was performed at Al Hussein University Hospital, Neurology Clinic, starting at January 2016 until January 2017. The study was conducted on Egyptian patients aged 3: 18 years with an affirmed diagnosis of epilepsy for one year or more. Data was gathered using a questionnaire performed by the interviewer. ADHD was diagnosed according to (DSM-IV TR).

Results: Our study included 160 epileptic children. In our sample 102 patients had Generalized Tonic-clonic seizures and 13 had Absence seizures, 45 patients had Partial epileptic seizures. (26.3\%) of the epileptic patients included had ADHD. We reported that partial epileptic seizure type; duration of epilepsy over 2 years and uses of more than one anti-epileptic drug were significantly associated with increased risk of having ADHD, and that having Partial epileptic seizures and use of more than one antiepileptic agent were independent predictors for ADHD.
\end{abstract}

Conclusions: $26.3 \%$ of epileptic children in this study had associated ADHD. Partial epileptic seizure type, duration of epilepsy over 2 years and use of more than one antiepileptic drug were significantly associated with ADHD.

Recommendations: Further studies are needed on large number of epileptic children. Keywords Epilepsy, ADHD, and children.

\section{INTRODUCTION}

Attention deficit hyperactivity disorder (ADHD) is a complex disorder, which can be seen as a disorder of lifetime, developing in preschool years and manifesting symptoms (full and/or partial) throughout the adulthood ${ }^{[1]}$.

ADHD is defined as a persistent pattern of inattention and/or hyperactivity-impulsivity that interferes with functioning or development. For fulfilling diagnostic criteria, ADHD must be associated with at least six symptoms of inattention and/or at least six symptoms of hyperactivity and impulsivity. Symptoms must be severe enough to interfere with functioning, must occur in at least two settings (i.e., school and home), and must have an age of onset before 12 years of age. ADHD can be subclassified into three subtypes predominantly inattentive presentation, predominantly hyperactive/impulsive presentation and Combined presentation ${ }^{[2]}$.

Based on family history, genotyping, and neuroimaging studies, there is clear evidence to support a biological basis for ADHD. ADHD has prevalence approximately 5 to $8 \%$ of school-aged children ${ }^{[3]}$ and about $2.5 \%-4 \%$ of adults ${ }^{[4]}$.

Regarding Egypt Farahat and coworkers [5] have reported general prevalence of ADHD 6.9\% among primary school children in Menoufia
Governorate. Another study reported that the prevalence of ADHD was approximately 6\% among third grade elementary school children in Assiut City ${ }^{[6]}$. The prevalence of ADHD is higher in children with epilepsy ${ }^{[7]}$. Population studies suggested that the prevalence of ADHD among epileptic children is ranging between 12 and $17 \%$ ${ }^{[8]}$. Other studies reported that among children with epilepsy, ADHD has been found to be ranging between $20 \%$ and $50 \%$ of patients [9]. Russ and coworkers ${ }^{[10]}$ reported that the prevalence of ADHD was $23 \%$ among children with epilepsy in the USA. In a community-based study in schools in UK, Reilly and coworkers ${ }^{[11]}$ reported that the prevalence of ADHD was 33\% among children with active epilepsy. Jones and coworkers ${ }^{[12]}$ found that children with epilepsy had statistically significantly higher rates of attention deficit hyperactivity disorder $(26.4 \%)$ in comparison group of healthy children (10\%).

Several mechanisms may account for the high prevalence of ADHD among epileptic patients, Kaufmann and coworkers ${ }^{[13]}$ proposed mechanisms explaining the epilepsy and ADHD comorbidity. The first hypothesis is that there are independent circumstantial factors; both ADHD and epilepsy are common in childhood and, therefore, may occur together. The second 
hypothesis is that there is a common underlying factor affecting neurochemistry and neurogenesis such as genetics, biochemistry (possibly adrenergic), or gene/environment interaction. The third hypothesis is that one condition has direct causative effects on the other condition. For example, the impact of clinical or subclinical epileptiform discharges on vigilance, memory, and processing speed ${ }^{[14]}$, the side effects of antiepileptic drugs (AEDs) such as topiramate that is associated with cognitive dulling ${ }^{[15]}$ and phenobarbital, which is associated with disinhibition ${ }^{[16]}$. There is a higher occurrence of ADHD Primarily Inattentive subtype in children with epilepsy and the reasons for this are not altogether clear ${ }^{[8]}$. Multiple factors must be considered in the evaluation of a child with epilepsy and hyperactivity or inattention. For instance, inattention could be due to subclinical seizures, undiagnosed learning disabilities, disturbed sleep as a result of a side effect of antiepileptic medication, or due to an Attention deficit disorder ${ }^{[17]}$.

\section{AIM OF WORK}

To detect the prevalence of ADHD among a sample of Egyptian children with idiopathic epilepsy in $\mathrm{Al}$ Hussein University Hospital, Neurology Clinic, and to determine associated risk factors.

\section{PATIENTS AND METHODS}

A cross-sectional study had been done at Outpatient Neurology Clinic at Al Hussein University Hospital from January 2016 until January 2017. During the period of one year, patients were joined to the study until the sample size reached 160 patients. The study was approved by the Ethics Board of Al-Azhar University and an informed written consent was taken from each participant in the study.

\section{Inclusion criteria:}

Egyptian patients aged from 3-18 years with a confirmed diagnosis of epilepsy for one year or more. Our sample included both males and females without discrimination.

\section{Exclusion criteria:}

- Patients aged less than 3 years, as it was difficult to diagnose ADHD before this age.

- Patients aged more than 18 years.

- Non-Egyptian patients.

- Patients known to have degenerative disease.

- Patients with a confirmed diagnosis of cerebral palsy

- Patients with global developmental delay.
Because all these conditions are known to be associated with ADHD. Informed consent has been signed by the parents/caretakers to participate in the research after explaining the purpose.

All data for the current study have been fulfilled (e.g. confirmed diagnosis, EEG findings, Drug treatment and response etc). Informations were obtained using a pre-tested questionnaire performed by the interviewer. The used questionnaire contained questions about age \& sex of children, duration and type of epilepsy, EEG abnormalities, current treatment and questions to assess ADHD. ADHD was diagnosed according to DSM-IV TR diagnostic criteria ${ }^{[18]}$. Seizures were classified using international classification of epileptic seizures ${ }^{[19]}$. Data were entered in to worksheet in Microsoft Excel and were analyzed using computer package SPSS 16.0 for windows.

\section{RESULTS}

This study included 160 children. 112 (70\%) patients were males and $48(30 \%)$ patients were female. Table (1) shows age distribution with mean age 8.5 years and standard deviation \pm 4.8 among males, while among females mean age 8.6 years and standard deviation \pm 4.7 .

Our sample included 115 (71.9\%) patients had generalized epileptic seizure of whom 102 $(63.8 \%)$ had generalized tonic-clonic seizures and $13(8.1 \%)$ had absence seizures. On the other hand, $45(28.1 \%)$ patients had partial epileptic seizures. Clinical characteristics of different seizure types are shown in table (2).

As shown in table (3), forty-two (26.3\%) epileptic patients included in our sample had ADHD spectrum disorders. Twenty-one patients (13.1\%) had combined type of ADHD (ADHD-C), Fifteen patients $(9.4 \%)$ had predominantly inattentive type (ADHD-I) and six patients (3.8\%) had predominantly hyperactive-impulsive type (ADHD-H). Table (3) showed the relations between sub-types of ADHD with sex, age category type of epileptic seizures, duration of epilepsy, current treatment and response to treatment.

Table (1): Age Distribution of the Study Population

\begin{tabular}{|c|c|c|c|c|}
\hline \multirow{2}{*}{ Age } & \multicolumn{2}{|c|}{ Male } & \multicolumn{2}{c|}{$\begin{array}{c}\text { Female } \\
(\mathrm{N}=112,70 \%)\end{array}$} \\
\cline { 2 - 5 } & No. & $\%$ & No. & $\%$ \\
\hline <6 years & 22 & 19.6 & 8 & 16.6 \\
6-9 years & 43 & 38.3 & 20 & 41.7 \\
10-12 years & 31 & 27.6 & 16 & 33.3 \\
$\geq 12$ years & 16 & 14.3 & 4 & 8.3 \\
\hline Mean \pm SD & \multicolumn{3}{|c|}{$8.5 \pm 4.8$} & \multicolumn{2}{c|}{$8.6 \pm 4.7$} \\
\hline
\end{tabular}


Table (2): Clinical Characteristic of Different Epileptic Seizure Types

\begin{tabular}{|c|c|c|c|c|c|}
\hline & $\begin{array}{c}\text { No.of } \\
\text { Patients }\end{array}$ & $\begin{array}{c}\text { Generalize Tonic Clonic } \\
\text { Seizures }\end{array}$ & $\begin{array}{l}\text { Absence } \\
\text { Seizures }\end{array}$ & $\begin{array}{c}\text { Partial Seizures }[\mathrm{N}= \\
45]\end{array}$ & P. Value \\
\hline Total & 160 & $102(63.7 \%)$ & $13(8.1 \%)$ & $45(28.1 \%)$ & \\
\hline \multicolumn{6}{|l|}{ Sex } \\
\hline Male & 112 & $82(80.4 \%)$ & $5(38.5 \%)$ & $25(55.6 \%)$ & \multirow{2}{*}{$\begin{array}{c}\mathrm{X} 2=7.5 \\
\mathrm{P}=0.023^{*}\end{array}$} \\
\hline Female & 48 & $20(20 \%)$ & $8(61.5 \%)$ & $20(44.4 \%)$ & \\
\hline \multicolumn{6}{|l|}{ EEG } \\
\hline Abnormal & 122 & $82(80.4 \%)$ & $9(69.2 \%)$ & $31(68.9 \%)$ & \multirow{2}{*}{$\begin{array}{l}\mathrm{X} 2=1.3 \\
\mathrm{P}=0.534\end{array}$} \\
\hline Normal & 38 & $20(19.6 \%)$ & $4(30.8 \%)$ & $14(31.1 \%)$ & \\
\hline \multicolumn{6}{|l|}{$\begin{array}{l}\text { Duration of } \\
\text { Epilepsy }\end{array}$} \\
\hline$<2$ Years & 140 & $88(86.3 \%)$ & $11(84.6 \%)$ & $41(91.1 \%)$ & \multirow{2}{*}{$\begin{array}{l}X 2=1.6 \\
P=0.454\end{array}$} \\
\hline$>2$ Years & 20 & $14(13.7 \%)$ & $2(15.4 \%)$ & $4(8.9 \%)$ & \\
\hline \multicolumn{6}{|c|}{$\begin{array}{l}\text { Family History of } \\
\text { epilepsy }\end{array}$} \\
\hline Present & 23 & $14(13.7 \%)$ & $1(7.7 \%)$ & $8(17.8 \%)$ & \multirow{2}{*}{$\begin{array}{r}\mathrm{X} 2=2.7 \\
\mathrm{P}=0.263\end{array}$} \\
\hline Absent & 137 & $88(86.5 \%)$ & $12(92.3 \%)$ & $37(82.2 \%)$ & \\
\hline \multicolumn{6}{|c|}{ Current Treatment } \\
\hline $\mathrm{S}$ & 114 & $82(80.4 \%)$ & $13(100 \%)$ & $19(42.2 \%)$ & \multirow{3}{*}{$\begin{array}{c}\mathrm{X} 2=44.7 \\
\mathrm{P}=0.001 * *\end{array}$} \\
\hline $\mathrm{C}$ & 19 & $0(0 \%)$ & $0(0 \%)$ & $19(42.2 \%)$ & \\
\hline $\mathrm{M}$ & 27 & $20(19.6 \%)$ & $0(0 \%)$ & $7(15.6 \%)$ & \\
\hline
\end{tabular}

* Statistically significant difference $(\mathrm{p}<0.05)$. $\mathrm{S}=$ sodium valproate, $\mathrm{C}=$ carbamazepine, $\mathrm{M}=$ multiple drugs

** Statistically significant difference $(\mathrm{p}<0.01)$

Table (3): Associations between ADHD/AD/HD and clinical characteristics of epilepsy patients

\begin{tabular}{|c|c|c|c|c|c|c|c|}
\hline & $\begin{array}{c}\text { N Of } \\
\text { Patients }\end{array}$ & ADHC-C & ADHD-I & $\begin{array}{c}\text { ADHD- } \\
\mathrm{H}\end{array}$ & P1 & $\mathrm{P} 2$ & P3 \\
\hline \multicolumn{8}{|l|}{ Sex } \\
\hline Male & $112(70 \%)$ & $17(51.5 \%)$ & $12(36.4 \%)$ & $4(12.1 \%)$ & \multirow{2}{*}{$\begin{array}{l}X 2=0.57 \\
P=0.449\end{array}$} & \multirow{2}{*}{$\begin{array}{l}X 2=0.03 \\
P=0.865\end{array}$} & \multirow{2}{*}{$\begin{array}{l}X 2=0.07 \\
P=0.792\end{array}$} \\
\hline Female & $48(30 \%)$ & $4(44.4 \%)$ & $3(33.3 \%)$ & $2(22.2 \%)$ & & & \\
\hline \multicolumn{8}{|l|}{ Age } \\
\hline$<10$ & $92(57.5 \%)$ & $17(70.8 \%)$ & $5(20.8 \%)$ & $2(8.4 \%)$ & \multirow{2}{*}{$\begin{array}{l}\mathrm{X} 2=4.7 \\
\mathrm{P}=0.03^{*}\end{array}$} & \multirow{2}{*}{$\begin{array}{l}X 2=2.37 \\
P=0.124\end{array}$} & \multirow{2}{*}{$\begin{array}{l}X 2=0.72 \\
P=0.396\end{array}$} \\
\hline$\geq 10$ & $68(42.5 \%)$ & $4(22.2 \%)$ & $10(55.6 \%)$ & $4(22.2 \%)$ & & & \\
\hline \multicolumn{8}{|c|}{$\begin{array}{l}\text { Type of Epileptic } \\
\text { Seizures }\end{array}$} \\
\hline $\mathrm{G}$ & $115(71.9 \%)$ & $9(47.4 \%)$ & $7(36.8 \%)$ & $3(15.8 \%)$ & \multirow{2}{*}{$\begin{array}{c}\mathrm{X} 2=8.43 \\
\mathrm{P}=0.004 * *\end{array}$} & \multirow{2}{*}{$\begin{array}{c}\mathrm{X} 2=4.3 \\
\mathrm{P}=0.038^{*}\end{array}$} & \multirow{2}{*}{$\begin{array}{r}\mathrm{X} 2=2.4 \\
\mathrm{P}=0.121\end{array}$} \\
\hline $\mathrm{P}$ & $45(28.1 \%)$ & $12(52.2 \%)$ & $8(34.8 \%)$ & $3(13 \%)$ & & & \\
\hline \multicolumn{8}{|l|}{$\begin{array}{l}\text { Duration of } \\
\text { Epilepsy }\end{array}$} \\
\hline$<2$ Years & $140(87.5 \%)$ & $11(44 \%)$ & $10(40 \%)$ & $4(16 \%)$ & \multirow{2}{*}{$\begin{array}{l}\mathrm{X} 2=14.89 \\
\mathrm{P}=0.001 * *\end{array}$} & \multirow{2}{*}{$\begin{array}{c}\mathrm{X} 2=4.45 \\
\mathrm{P}=0.035^{*}\end{array}$} & \multirow{2}{*}{$\begin{array}{l}\mathrm{X} 2=3.61 \\
\mathrm{P}=0.058\end{array}$} \\
\hline$>2$ Years & $20(12.5 \%)$ & $10(58.8 \%)$ & $5(29.4 \%)$ & $2(11.8 \%)$ & & & \\
\hline \multicolumn{8}{|c|}{ Number of Drugs } \\
\hline Single Drug & $135(84.4 \%)$ & $12(50 \%)$ & $10(41.6 \%)$ & $2(8.4 \%)$ & \multirow{2}{*}{$\begin{array}{c}\mathrm{X} 2=8.57 \\
\mathrm{P}=0.003 * *\end{array}$} & $X 2=2.09$ & \multirow{2}{*}{$\begin{array}{c}\mathrm{X} 2=7.05 \\
\mathrm{P}=0.008 * *\end{array}$} \\
\hline$>$ One Drug & $25(15.6 \%)$ & $9(50 \%)$ & $5(27.8 \%)$ & $4(22.2 \%)$ & & $\mathrm{P}=0.148$ & \\
\hline
\end{tabular}

G: Generalize epileptic seizure and includes Generalize tonic clonic and absence seizures. P: Partial seizures 
Partial epileptic seizure $[\chi 2=18.7, \quad \mathrm{p}=0.001]$, duration of epilepsy over 2 years $[\chi 2=27.4, p=0.001]$ and use of more than one anti-epileptic drug $[\chi 2=19.4$, $\mathrm{p}=0.001]$ were significantly associated with increased risk of having one of ADHD spectrum disorders (ADHD-C, ADHD-I or ADHD-H).

Partial epileptic seizure $[\chi 2=8.418, p=0.004]$ as well as use of more than one anti-epileptic drug $[\chi 2=8.46, \mathrm{p}=0.003]$ have significant association with ADHD combined type (ADHD-C).

Partial epileptic seizure $[\chi 2=4.4, p=0.04]$ and duration of epilepsy for more than 5 years had significant association with ADHD inattentive type (ADHD-I). The use of more than one anti-epileptic drug $[\chi 2=7.03, p .006]$ had significant association with ADHD hyperactive-impulsive type (ADHD-H).

Multi-variant logistic regression analysis had been performed to evaluate the risk factors for ADHD spectrum disorders among epileptic children in our study, including patient age, sex, type of epileptic seizure, duration of epilepsy and number of drugs used.

Our results showed that patient age and sex are not significant risk factors for the development of ADHD spectrum disorders in epileptic children.

Results also revealed that risk factors for the development of ADHD spectrum disorders in epileptic children were: diagnosis of partial epileptic seizure $[(\mathrm{OR}=6.2),(95 \% \mathrm{CI} 2.6-15)]$, use of more than one antiepileptic agent $[(\mathrm{OR}=6.2),(95 \% \mathrm{CI} 2.6-15.0)]$ and duration of epilepsy more than 2 year $[(\mathrm{OR}=8.7)$, (95\% CI 3-25.6)].

\section{DISCUSSION}

The current study revealed prevalence of ADHD spectrum disorders (26.3\%) compared to general population values $(3.4 \%)^{[20]}$. This result is also close to the prevalence of $(26.4 \%)$ that was estimated by Jones and coworkers ${ }^{[12]}$. The prevalence of ADHD in our study is consistent with those reported by Russ and coworkers $(23 \%)^{[10]}$, by Gad and coworkers [21] $(29.2 \%)$ and prevalence of $29 \%$ that reported by Ranawaka and coworkers ${ }^{[22]}$.

Clinical studies suggest a prevalence of ADHD among children with epilepsy to range from $30 \%$ to $40 \%$ as reported by Dunn and Kronenberger ${ }^{[23]}$ and from $20 \%$ to $50 \%$ as reported by Williams and coworkers ${ }^{[9]}$.

Our study results varied with the rate of $2.3 \%$ found by Socanski and coworkers ${ }^{[23]}$ and 33\% that estimated by Reilly ${ }^{[8]}$.

In our sample, the most common subtype of ADHD was the combined type of ADHD (ADHD-C) (13.1\%), followed by inattentive type (ADHD-I) $(9.4 \%)$ and lastly the hyperactive impulsive type (ADHD-H) $(3.8 \%)$. This is consistent with that reported by Gonzalez and coworkers ${ }^{[24]}$ that, just like in the general population, the most common type among epileptic children is combined type. This is different from other studies that recorded that the inattentive presentation of ADHD appears to be the most common in the epilepsy population, such as Dunn and Kronenberger [23], Sherman and coworkers ${ }^{[26]}$ and Reilly ${ }^{[8]}$.

The Number of males was three times as great as the number of females (2.3:1) in our study. The male to female ratios for the combined subtype (4.3:1), for the inattentive subtype (4:1) and for hyperactive subtype (2:1). These ratios are similar to ratios reported in the literature.

Our study revealed that male patients were three times more likely to develop ADHD, especially in the combined or hyperactive/impulsive subtypes. These data are consistent with results estimated by Miller and coworkers ${ }^{[27]}$, which indicated the male predominance $(70 \%)$, reported for 88 hyperactive/ impulsive ADHD patients in the US ${ }^{[27]}$. Those results were similar to our findings showing that ADHD was significantly higher in males and was most often the combined type. This raises the question of etiological similarities causing both ADHD and epilepsy. Several possible explanations could be made for the association between ADHD symptoms and epilepsy. These might be neurological dysfunction, seizure variables, medication effects or psychosocial response to epilepsy. Male to female ratios were similar to the figures commonly reported for this syndrome [overall prevalence of current DSM-IVlike ADHD was $9.2 \%$ with a male: female ratio of 2.28:1] ${ }^{[28]}$.

Our study reported that patient age was not significant risk factors for the development of ADHD spectrum disorders in epileptic children, which is quite similar to that reported by Dunn and coworkers ${ }^{[29]}$.

Our study reported significant correlation between ADHD (combined and hyperactiveimpulsive subtype) and partial epileptic seizure type. This is different from the findings of Dunn and coworkers ${ }^{[29]}$ who estimated that seizure type is not predictors of symptoms of ADHD. This also varies with results found by Hempel and coworkers ${ }^{[30]}$ who reported that children with intractable generalized seizures were more likely to meet diagnostic criteria for ADHD. This difference might be due to sample variability, as we did not have a separate group of intractable epilepsy. Moreover, Elisabeth and Daniel ${ }^{[31]}$ reported that children with ADHD inattention type were more likely to have localization related epilepsy than generalized epilepsy. It is well established that patients with partial epileptic seizure type have more frequency of 
structural cerebral lesions in comparison with those with generalized epilepsy. Moreover, the structural cerebral lesions are known as one of the etiological factors that take part in the ADHD development ${ }^{\left[{ }^{32} \text {. }\right.}$ Our results suggested that the ADHD symptoms are significantly higher in patients who had epilepsy for more than 2 years. This result is similar to that reported by Gad and coworkers ${ }^{[21]}$. This may be due to chronic effects of seizures or prolonged use of antiepileptic drugs. This is different from the finding of Sherman and coworkers [26], who reported that duration of epilepsy is not related to severity of inattention or hyperactivity/impulsivity.

A study reported that there is a significant relation between prolonged treatment with Sodium Valproate and development of ADHD ${ }^{[33]}$. Our results revealed that use of more than one antiepileptic drug was significantly associated with ADHD. This is consistent with what reported by Gad and coworkers ${ }^{[21]}$. This is supported by the findings of Williams et al. [34] who noted that children on polytherapy had significantly lower verbal and visual memory scores than children on monotherapy ${ }^{[34]}$.

Without information about duration of exposure and dosage or blood levels, it is not possible to make any conclusions on antiepileptic drugs and symptoms of ADHD. In most psychiatric samples, ADHD was more common in males than females and is most often the combined type.

\section{Conclusions}

ADHD is a common co-morbid condition among the children with epilepsy in our study. Some factors are reported to be significantly associated with increased risk of having a disorder in the ADHD spectrum: Partial epileptic seizure type, duration of epilepsy over 2 years and use of more than one anti-epileptic drug. Having partial epileptic seizures and use of more than one antiepileptic agent were independent risk factors for the development of ADHD spectrum disorders in epileptic children.

\section{RECOMMENDATIONS}

Further large studies are needed to be performed on large number of children with epilepsy to detect the prevalence of ADHD among epileptic and to determine the nature of the co-morbidity of these two conditions. Screening for ADHD should be a part of epileptic patient comprehensive evaluation. Further study to assess the effect of treatment of ADHD on epileptic patients is recommended.

\section{REFERENCES}

1.Singh A, Yeh CJ, Verma N, and Das AK (2015): Overview of Attention Deficit Hyperactivity Disorder in Young Children. Health Psychol Res.,3(2): 2115

2.AmericanPsychiatricAssociation (2013): Diagnostic and Statistical Manual of Mental Disorders DSM-5. 5th ed. Washington, DC.

3.Sadock BJ and Sadock VA (2015): Kaplan and Sadock's Synopsis of psychiatry, Eleventh edition. Wolters Kluwer. Pp: 2454:78

4.Polanczyk GV, Willcutt EG, Salum GA, Kieling C and Rohde LA (2014): ADHD prevalence estimates across three decades: an updated systematic review and meta-regression analysis. Int $\mathrm{J}$ Epidemiol.,43(2), Pp: 434-442.

5.Farahat T, Alkot M, Rajab A and Anbar $R$ (2014): Attention-Deficit Hyperactive Disorder among Primary School Children in Menoufia Governorate, International Journal of Family Medicine, 2014: 257369.

6.El-Tallawy HN, Hassan WA, El-Behary AA, Shehata GA (2005): Prevalence of attention deficit hyperactivity disorder among elementary schools children in Assiut City-Egypt, Egypt J. Neurol. Psychiat. Neurosurg.,42: 517-526.

7.AbdEINaby SA and Naguib YM (2018): Sociodemographic, Electrophysiological, and Biochemical Profiles in Children with Attention Deficit Hyperactivity Disorder and/or Epilepsy. Behav Neurol.,2018: 8932817.

8.Reilly CJ (2011): Attention deficit hyperactivity disorder in childhood epilepsy. Res Dev Disabil., 32(3): Pp: 883-93.

9.Williams AE, Giust JM, Kronenberger WG and Dunn DW (2016): Epilepsy and attention-deficit hyperactivity disorder: links, risks, and challenges. Neuropsychiatr Dis Treat., 12: 287-296.

10.Russ SA, Larson $K$ and Halfon N (2012): A national profile of childhood epilepsy and seizure disorder. Pediatrics , 129: 256-64.

11.Reilly C, Atkinson $P$ and Das KB (2014): Neurobehavioral co-morbidities in children with active epilepsy: a population-based study. Pediatrics , 133: e1586-93.

12.Jones JE, Watson $R$ and Sheth $R$ (2007): Psychiatric comorbidity in children with new onset epilepsy. Dev Med Child Neurol ., 49: 493-507.

13.Kaufmann R, Goldberg-Stern $H$ and Shuper A (2009): Attention-deficit disorders and epilepsy in childhood: incidence, causative relations and treatment possibilities. J Child Neurol., 24 (6): 727-33

14.Austin JK, Harezlak J, Dunn DW, Huster GA, Rose DF and Ambrosius WT (2001): Behavior problems in children before first recognized seizures. Pediatrics, 107(1): 115-22.

15.Martin R, Kuzniecky R, Ho S, Hetherington H, Pan J, Sinclair K, Gilliam F and Faught $E$ (1999): Cognitive effects of topiramate, gabapentin, and lamotrigine in healthy young adults. Neurology, 52(2): 321-7.

16.Bourgeois BF(1998): Antiepileptic drugs, learning, and behavior in childhood epilepsy. https://www.ncbi.nlm.nih.gov/pubmed/9738670

17.Schubert $\mathbf{R}$ (2005): Attention deficit disorder and epilepsy. Pediatric Neurology, $32: 1-10$

18.American Psychiatric Association (2004): Diagnostic and Statistical Manual of Mental Disorders, Text Revision, American Psychiatric Association,, American 
Psychiatric, Washington, DC, USA, 4th edition.

19.BergNeil AT and Blackstone W (2006): Concepts in classification and their relevance to epilepsy. Epilepsy Research , 70 : 11-19.

20.Fayyad J, De Graaf R, Kessler $\mathbf{R}$ and Alonso J (2007): Cross-national prevalence and correlates of adult attention-deficit hyperactivity disorder. British Journal of Psychiatry, 190:402-409

21.Gad EF, El-tayeb AA and Shabaan I (2017): Prevalence of Attention-Deficit Hyperactivity Disorder in Children with Idiopathic Epilepsy at Assiut Children University Hospital. American Journal of Medicine and Medical Sciences , 7(2): 87-91

22.Ranawaka R, Karunaratne $K$ and Mettananda DG (2016): Attention-Deficit Hyperactivity Disorder in Childhood Epilepsy. J Neurol Neurol SciDisord., 2(1): 004-006.

23.Dunn DW and Kronenberger WG(2005): Attention Problems, and ADHD: Review and Practical Considerations. Seminars in Pediatric Neurology, 12(4): 222-228. B.

24.Socanski D, Aurlien D, Herigstad A, Thomsen PH and Larsen TK (2013): Epilepsy in a large cohort of children diagnosed with attention deficit/hyperactivity disorders (ADHD). Seizure-European Journal of Epilepsy, 22(8): 651-655.

25.Gonzalez-Heydrich J, Dodds A, Whitney J, MacMillan, C, Waber D, Faraone SV and Biederman J (2007): Psychiatric disorders and behavioral characteristics of pediatric patients with both epilepsy and attention-deficit hyperactivity disorder. Epilepsy and Behavior, 10(3): 384-388.

26.Sherman EM, Slick DJ, Connolly MB and Eyrl KL (2007): ADHD, neurological correlates and health- related quality of life in severe pediatric epilepsy. Epilepsia, 48(6): 1083-91.

27.Miller DJ, Derefinko KJ, Lynam DR, Milich R and Fillmore MT (2010): Impulsivity and Attention DeficitHyperactivity Disorder: Subtype Classification Using the UPPS Impulsive Behavior Scale. J Psychopathol Behav Assess., 32: 323-26.

28. Ramtekkar UP, Reiersen AM, Todorov AA and Todd RD (2010): Sex and age differences in attentiondeficit/hyperactivity disorder symptoms and diagnoses: implications for DSM-1V and ICD-11. J Am Acad Child Adolesc Psychiatry, 49: 217-228.

29.Dunn DW, Austin JK, Harezlak J and Ambrosius WT (2003): ADHD and epilepsy in childhood. Journal of Developmental Medicine and Child Neurology, 1: 5054

30.Hempel AM, Frost MD, Ritter FJ and Farnham S (1995): Factors influencing the incidence of ADHD in pediatric epilepsy patients. Epilepsia,36: 122-128

31.Elisabeth MS and Daniel JS (2007): Neurological Correlates and Health - related Quality of Life in Severe Paediatric Epilepsy. Epilepsia,48: 1083-1091.

32.Cendes F, Theodore WH, Brinkmann BH, Sulc V and Cascino G (2016): Neuroimaging of epilepsy. Handb Clin Neurol.,136: 985-1014.

33.Wei L and Kelly YC (1999): Sodium Valproate: Culprit or Savior of Attention Deficit Hyperactivity Disorder? Hong Kong Journal of Psychiatry, 9: 29-30.

34.Williams J, Sharp G, Lange $B$ and Thomas $P$ (1996): The effects of seizure type, level of seizure control, and antiepileptic drugs on memory and attention skills in children with epilepsy. Developmental Neuropsycology, 12: 241-2. 